\section{Negative Binomial Distribution to Explain the Domestic Fire Incidence in Nepal}

Arun Kumar Yadav' and Santosh Kumar Shah" ${ }^{2 *}$

Submitted: 30 August 2021; Accepted: 10 November 2021

Published online: 5 December 2021

DOI: https://doi.org//0.3126/njs.v5il.4I 229

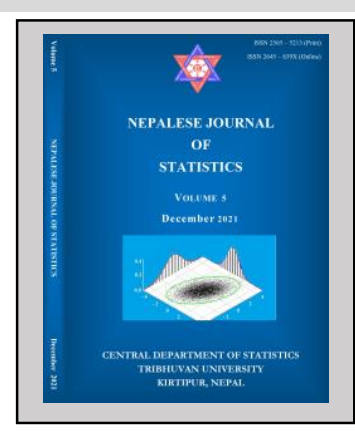

\title{
ABSTRACT
}

\section{ABSTRACT}

Background: Fire disaster is one of the most destructive disasters. According to global dataset of Sendai Framework, domestic fire incidence was $9.9 \%$ up to 2019 . In Nepal, $62 \%$ fire incidence was reported during 2017 and 2018 . However, many studies have been conducted on fire incidence, few of them are based on domestic fire incidence.

Objective: To find the descriptive statistics of fire occurrences and fire fatalities, and to identify the probability distributions that best fit the data of fire occurrences observed in three ecological regions as well as overall in Nepal.

Material and Methods: The data of fire incidences from May 201I to April 202I were retrieved from Nepal Disaster Risk Reduction Portal, Government of Nepal. At first, a statistical software "Mathwave EasyFit" of 30 days trial version was used to identify the candidate probability models. Further, the best probability model was determined after testing the goodness of fit of the candidate models by using graphical tools-histogram and theoretical densities, empirical and theoretical CDFs, Q-Q plot and P-P plot; and mathematical tools-maximum likelihood, Akaike Information Criteria and Bayesian Information Criteria by using the package "fitdistrplus" of software $R$ version 4.I.I.

Results: On an average, 135 fire incidences per month were occurred in Nepal. However, the Terai faced the highest monthly fire incidences compared to the Hill and the Mountain, it has less fatality per 100 fire incidence followed by the Hill and the Mountain. Descriptive statistics reveals that fire occurrences are moderate during November to February and high in March and April. The fire incidences were reported high during spring and winter and low during summer and autumn season which reveals that fire incidence might be related with the precipitation and temperature. The sample data was run in "Mathwave EasyFit" software which suggested Poisson, geometric and negative binomial distribution as candidate probability models. The goodness of fit of these models were further tested by graphical as well as mathematical tools where negative binomial distribution was found to be best among the candidate models for the data set. 
Conclusion: Incidence of fire disasters varies by ecological regions as well as by seasons. It is low in the Mountain region and during Monsoon/rainy season. Negative binomial distribution fits the best to monthly data of fire incidence in Nepal.

Keywords: Domestic fire incidence, negative binomial distribution, Akaike Information Criteria and Bayesian Information Criteria, P-P plot, Q-Q plot.

Address correspondence to the author: Central Department of Statistics, Tribhuvan University, Kirtipur, Kathmandu, Nepal', 2 .Email: arunyadav125@gmail.com'; santoshshah1234@yahoo.com ${ }^{2 *}$ (Corresponding author email)

\section{INTRODUCTION}

Fire disaster is one of the most destructive disasters. The major sources of domestic fires are cooking, heating and use of electrical gadgets. It causes destruction to household properties, loss of life and injuries. According to global dataset of Sendai Framework for disaster risk reduction, $9.9 \%$ disaster incidences were of domestic fire, due to which 17,762 people were loss their lives, 63,784 people were injured and I,433 people were missing up to 2019 (UNDRR, 2019). World Health Organization (WHO) reported that an estimated 180,000 people lost their lives every year caused by burns. Among these, vast majority occur in low- and middle-income countries (WHO, 2018). Nepal is one of the most disaster-prone countries where domestic fire is the leading disaster incident among the listed disasters types in Ministry of Home Affairs dataset. Nepal Disaster Report, 2019 revealed that out of 6,38I disaster events during 2017 and 20I8, altogether 3973 (62\%) were fire incidents followed by landslide, lightening and flood (Ministry of Home Affairs [MoHA], 2019). The effect of fire disasters in economic losses, damaging house completely and injuries was highest among all disasters whereas fourth highest in fatalities (MoHA, 2019). Globally, issues of fire disasters have attracted a lot of attentions of the researchers (Mckenzie, Petereson, \& Agee, 2000; Wang, Lu, \& Li, 2005; Cheng and Wang, 2008; Bistinas, Harrison, Prentice, \& Pereira, 20I4; D'Este et al., 2020; Boadi, et. al., 2015). Most of these studies are based on forest fire frequency data (Mckenzie, Petereson, \& Agee, 2000; Wang, Lu, \& Li, 2005, 2005; Cheng and Wang, 2008; Bistinas et. al. 2014) whereas a very few studies are on domestic fire frequency data (Boadi et. al.,2015).

Several studies provide models that are useful to measure the likelihood of the fire frequency to prevent forest fire disaster (Zhang et al., 20I I; Bistinas et al., 20l4; D'Este et al., 2020), whereas others provide information needed for fire management decisions (Wang, Lu, \& Li, 2005; Taylor, Woolford, Dean, \& Martell, 20I3). Bartak, Gdulova, Spatenkova, Barta and Simova (2014) used a prediction model based on logistic regression to estimate the probability of building fires based on different predictors. Mckenzie, Petereson and Agee (2000) used non-linear multiple regression models to predict fire return intervals on the basis of different predictors. However, Boadi, Harvey and Gyeke-dako (2015) conducted the fitting of probability distribution on domestic fire frequency data of Ghana and estimated the parameters of the distribution fitted to the data. 
Distribution fitting is the process used to select a statistical distribution that best fits a set of data so that one can predict the probability or to forecast the frequency of occurrence of the magnitude of the phenomenon in a certain interval. There are many distributions and choosing a suitable distribution is a critical and challenging problem. However, the characteristics of the phenomena and of the distribution help to choose appropriate statistical distribution. Since fire occurrence is a rare event, nature of monthly fire frequency seems to be righted tailed, monthly fire occurrence - discrete count data - are generally analyzed using count data models like a Poisson model, negative binomial model (NB), zero-inflated models, and hurdle models (Xiao, Zhang, \& Ji, 2015). Boadi, Harvey and Gyeke-dako (2015) used negative binomial distribution and Poisson distribution in the study "Modelling of fire count data: fire disaster risk in Ghana". The objective of the study is to find the descriptive measures of fire occurrences and fire fatalities recorded in Nepal. The major objective of this study is to identify the probability distribution that best fits data of fire occurrences in Nepal. Moreover, the paper is also focused on disaggregation to identify the probability distribution that best fits the fire incidence data of three ecological regions of Nepal.

\section{MATERIALS AND METHODS}

\section{Data}

This study is based on secondary data of fire occurrence frequency in Nepal. The data is freely available on the official website http://drrportal.gov.np/ of Nepal Disaster Risk Reduction Portal, Government of Nepal. The data of fire incidences by ecological regions as well as by months were retrieved from Nepal Disaster Risk Reduction Portal, Government of Nepal (Government of Nepal [GoN], 202I). Further, data from May 20II to April 202I by 3 ecological regions were used in this study.

\section{Data analysis}

Different discrete probability distributions such as binomial, Poisson, and negative binomial are commonly used to represent the distribution of count data. Poisson distribution is the most suitable distribution for the analysis of an underlying count data with constant rate of occurrence (Bolker 2008; O'Hara \& Kotze 2010; Puig \& Valero, 2015). However, the assumption that the variance equals the mean often does not hold for many practical situations, it does not fit the data because of over-depressiveness nature of the data. In such cases, negative binomial distribution is appropriate to fit the data (Puig \& Valero, 2015; Hilbe, 2014). The "Mathwave EasyFit", statistical software, is used to identify the probable candidate models of probability distributions that might best fit the sample data. Based on the nature and the structure of the fire incidence data of Nepal, the following three probability distributions were explored.

\section{Poisson distribution}

It is a discrete probability distribution which is used to find the probability of a given number of events, occur with a known constant mean rate and independently of the time since last event, happening in a fixed interval of time. The Probability Mass Function (PMF) of observing any specific count $\mathrm{x}$, over time $\mathrm{t}$ is given as; 


$$
\mathrm{P}(\mathrm{X}=\mathrm{x}, \mu \mathrm{t})=\frac{\mathrm{e}^{-\mu \mathrm{t}} \times(\mu \mathrm{t})^{\mathrm{x}}}{\mathrm{x} !}, \mathrm{x}=0,1,2, \ldots \ldots \ldots \ldots \ldots \ldots
$$

Here, $\mu>0$, average rate per unit time, is the parameter of the distribution. In estimating the model parameters, the method of Maximum Likelihood Estimation (MLE) is the most versatile method for fitting parametric statistical models to data (Cousineau et al. 2004). It estimates the values of the true parameters that are most likely to the observed data. The MLE of the parameter $\mu$ is $\hat{\mu}=\bar{X}$, the sample mean.

\section{Negative binomial distribution}

It is a discrete probability distribution which is used to calculate the probability of nonnegative over dispersed discrete random variable. The probability mass function (PMF) of this distribution is given as

$\mathrm{P}(\mathrm{X}=\mathrm{x})=\frac{\Gamma(\mathrm{x}+\mathrm{k})}{\mathrm{x} ! \Gamma(\mathrm{k})}\left[\frac{\mathrm{k}}{\mu+\mathrm{k}}\right]^{\mathrm{k}}\left[\frac{\mu}{\mu+\mathrm{k}}\right]^{\mathrm{x}} \quad$ for $\mathrm{x}=0,1,2, \ldots \ldots \ldots \ldots$

Where $\mu$ and $\mathrm{k}$ are the parameters. The mean and variance of the distribution are $\mathrm{E}(\mathrm{X})=\mu$ and

$\operatorname{var}(\mathrm{X})=\mu+\frac{\mu^{2}}{\mathrm{k}}$. As ' $\mathrm{k}$ ' - the size of the distribution - is one, the distribution becomes a geometric distribution and as ' $k$ ' tends to infinity, the distribution becomes Poisson distribution where mean is equal to variance. The maximum likelihood estimator of the parameter $\mu$ will be $\hat{\mu}=\bar{X}$, the sample mean. Another parameter ' $\mathrm{k}$ ' is used to estimate through iteration by using Newton - Raphson Method (Walsh, 1975).

\section{Geometric distribution}

It is a discrete probability distribution which represents the distribution of failure for getting first success in a binomial trial. The probability mass function (PMF) of this is $P(X=x)=p(I-p)^{x-1}$ for $x=1,2,3, \ldots \ldots .$.

where $p$, the unique parameter, denotes the probability of success in each independent trial. Geometric distribution is a special case of negative binomial distribution. The special case of size (k) of negative binomial distribution is equal to I. The mean and variance are $\frac{1}{p}$ and $\frac{1-p}{p^{2}}$.

\section{Goodness of fit}

The Log-likelihood, Akaike Information Criteria (AIC) and Bayesian Information Criteria (BIC) statistics are used as tools for testing of goodness of fit to select the best model among the candidate models. The goodness of fit of the suggested models from the "Mathwave EasyFit" software of 30 days trial version and histograms were further diagnosed by using Cumulative Probability Function (CDF), P-P plot and Q-Q plot, Log-likelihood, AIC and BIC statistics. P-P (probability-probability) plot is a graphical presentation of cumulative density function (CDF) that plots CDF of empirical distribution against CDF of a candidate theoretical distribution. If a probability distribution fits the data, the CDFs of empirical and theoretical distributions form a straight line on a 45 degree. To compare the empirical distribution and theoretical distribution, it is checked whether the points lie on the 45-degree line. Deviation of points from the line indicates 
the distributions differ from each other. P-P plot is more sensitive to the deviation of the empirical distribution and theoretical distribution in the middle of the distribution but less at the tails.

Q-Q (quantile-quantile) plot is a graphical method used to compare the probability distributions (empirical and specified theoretical) by plotting their quantiles against each other. Quantile is a set of value which divides the range of a probability distribution in continuous intervals with equal probabilities. On a Q-Q plot, there is a base line - a straight line on a $45^{\circ}$ which is dependent on the location and scale parameters of the candidate theoretical distribution. Every point on the $\mathrm{Q}-\mathrm{Q}$ plot corresponds to one of the quantiles of empirical distribution placed on vertical axis plotted against the same quantiles of the theoretical distribution placed on horizontal axis. Points closer to base line reflect the better fit of the candidate distribution. Q-Q plot is more sensitive to the deviation of the empirical distribution and theoretical distribution at the tails of the distribution but less at the middle. The AIC and BIC are used widely in applied statistics as model selection criteria (Lumley T \& Scott A, 20I5). The AIC and BIC for a model is generally written in the form $[-2 \log L+k p]$, where $L$ represents the likelihood function, $p$ denotes the number of parameters in the model, and $k$ is 2 for AIC and $\log (n)$ for BIC (Dziak, Coffman, Lanza, \& Li, 20I2). Since AIC is an estimate of a constant summed to the relative distance between the unknown true likelihood function of the data and the fitted likelihood function of the model, the lower AIC indicates that a candidate model is closer to the truth. Under a certain Bayesian setup, $\mathrm{BIC}$ is an estimate of a posterior probability function of a model being true, so lower BIC suggests that a candidate model is more likely to be the true model. The best fitted model is identified by the minimum value of the BIC and AIC (Boadi, Harvey, \& Gyeke-dako, 20I5). However AIC is used for model selection in applied statistics, when sample size $(n)$ is small relative to large number of parameters(P) i. e. $\frac{n}{p}$ is not greater than $40, \mathrm{AIC}$ needs second order bias correction (Burnham and Anderson, 2004). The corrected AIC is

$$
\mathrm{AIC}_{\mathrm{c}}=-2 \log L+2 \mathrm{p}+\mathrm{AIC}+\frac{2 p(p+1)}{n-p-1}
$$

\section{RESULTS}

\section{Descriptive statistics}

Histogram plots (Figure I) provides the monthly fire occurrence frequency of three ecological regions: Mountain, Hill and Terai, and overall of Nepal. The blue lines overlaying on histogram represent the mean values of the fire occurrence frequency. The average number of fire occurrence in a month was found to be the highest in the Terai region (72) followed by the Hill (53) and the Mountain (10). 

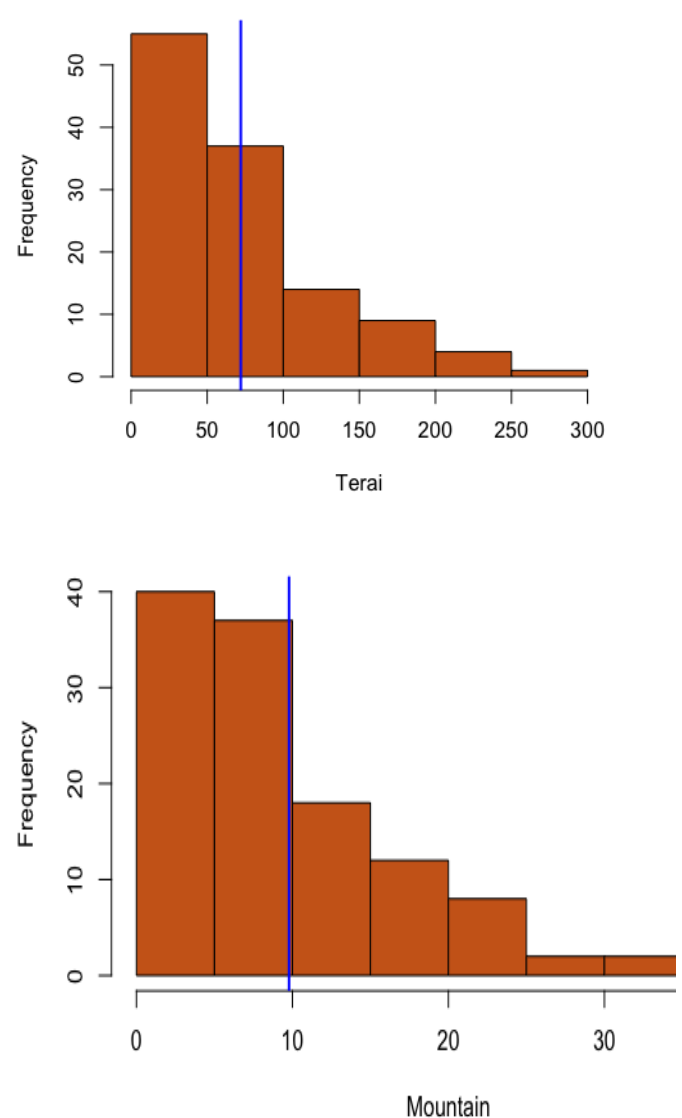
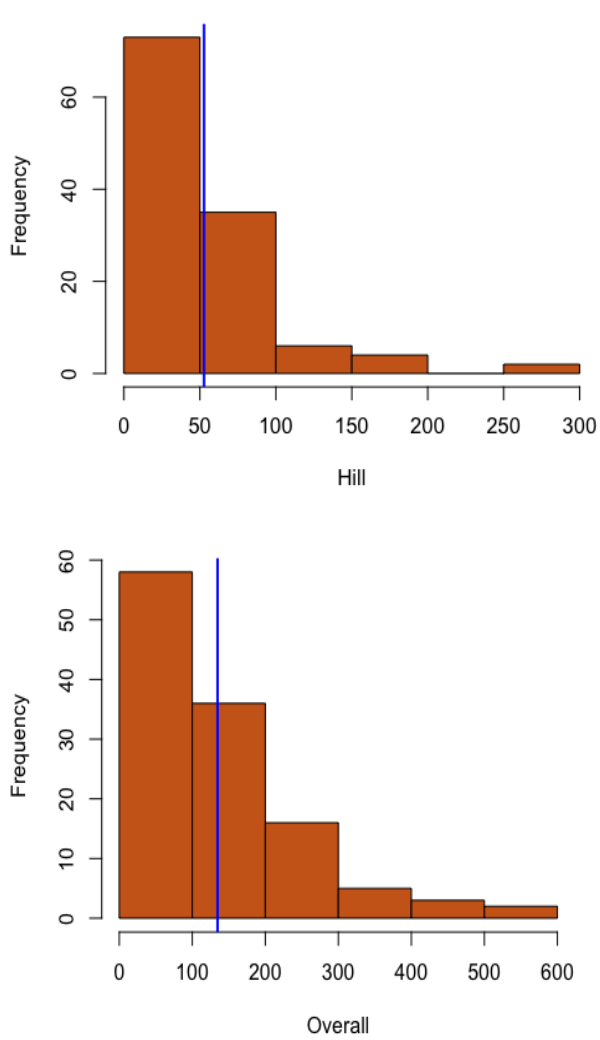

Fig. I. Histograms representing monthly fire occurrences by ecological region of Nepal.

Figure 2 summarizes the histogram plots of the fatality from fire occurrence in three ecological regions: Terai, Hill and Mountain, and overall of Nepal. The blue lines overlying on histogram indicate the average of fire fatality which is highest in the Hill (3) followed by the Terai (2) and the Mountain (I). The average of overall fire fatality was found to be 6 . 

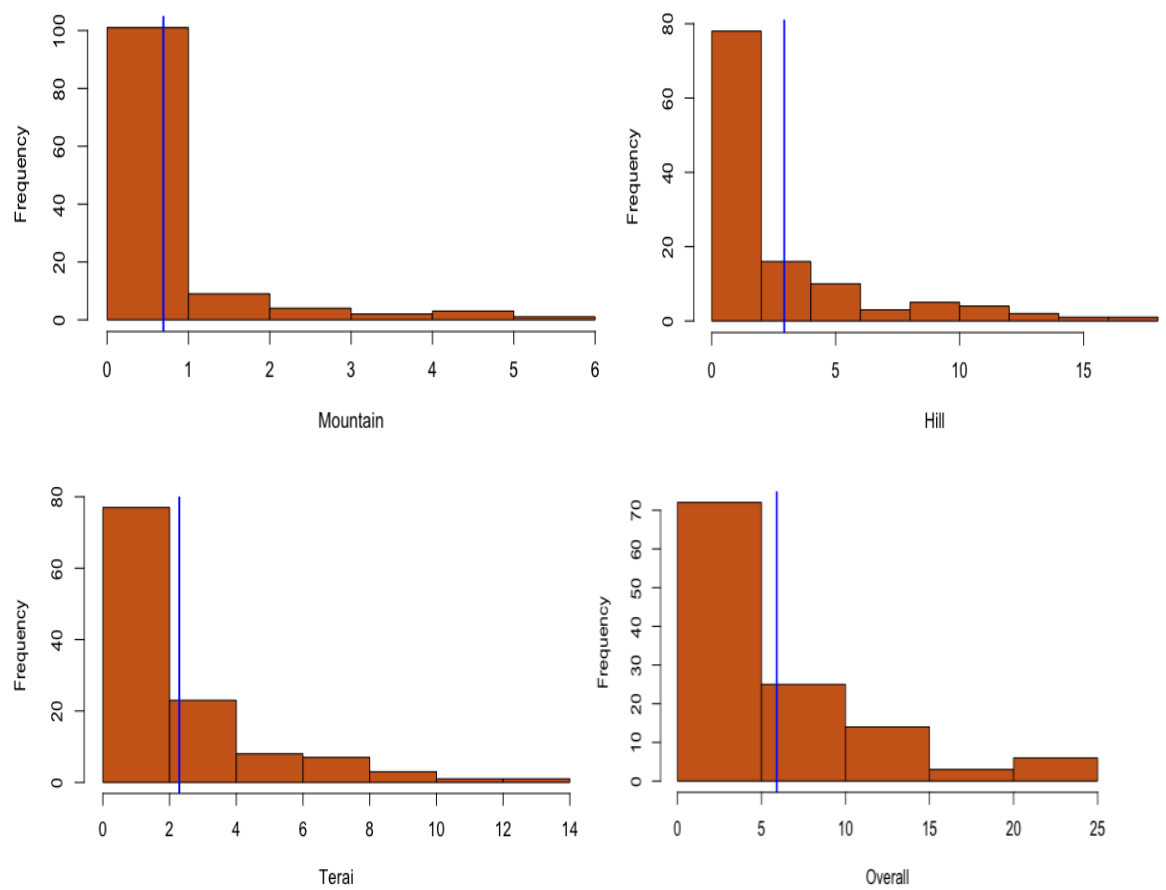

Fig. 2. Histograms representing fire fatality by ecological regions of Nepal.

The visual presentation in Figure 3 represents how fire occurrences and fatality from fire are distributed in months as well as in seasons along different ecological regions of Nepal. It depicts that frequency of fire was found to be slightly decreasing in the month of February compared to January then increased rapidly to the month of April. After experiencing the highest frequency in April, fire occurrence decreased gradually till the month of September then again it followed the trend of increasing to the end of year. Observing the line chart of fatalities that are the consequences of fire, it is remarkable that the months-December, January, February, March and April experienced higher monthly fire fatalities. Fire occurrences recorded over the study period were plotted providing an indication of the severity of fire frequency and fire fatality from it. Average fire occurrence was found to be minimal in summer and picked in spring whereas average fatality from fire was observed to be low in summer and high in winter. 


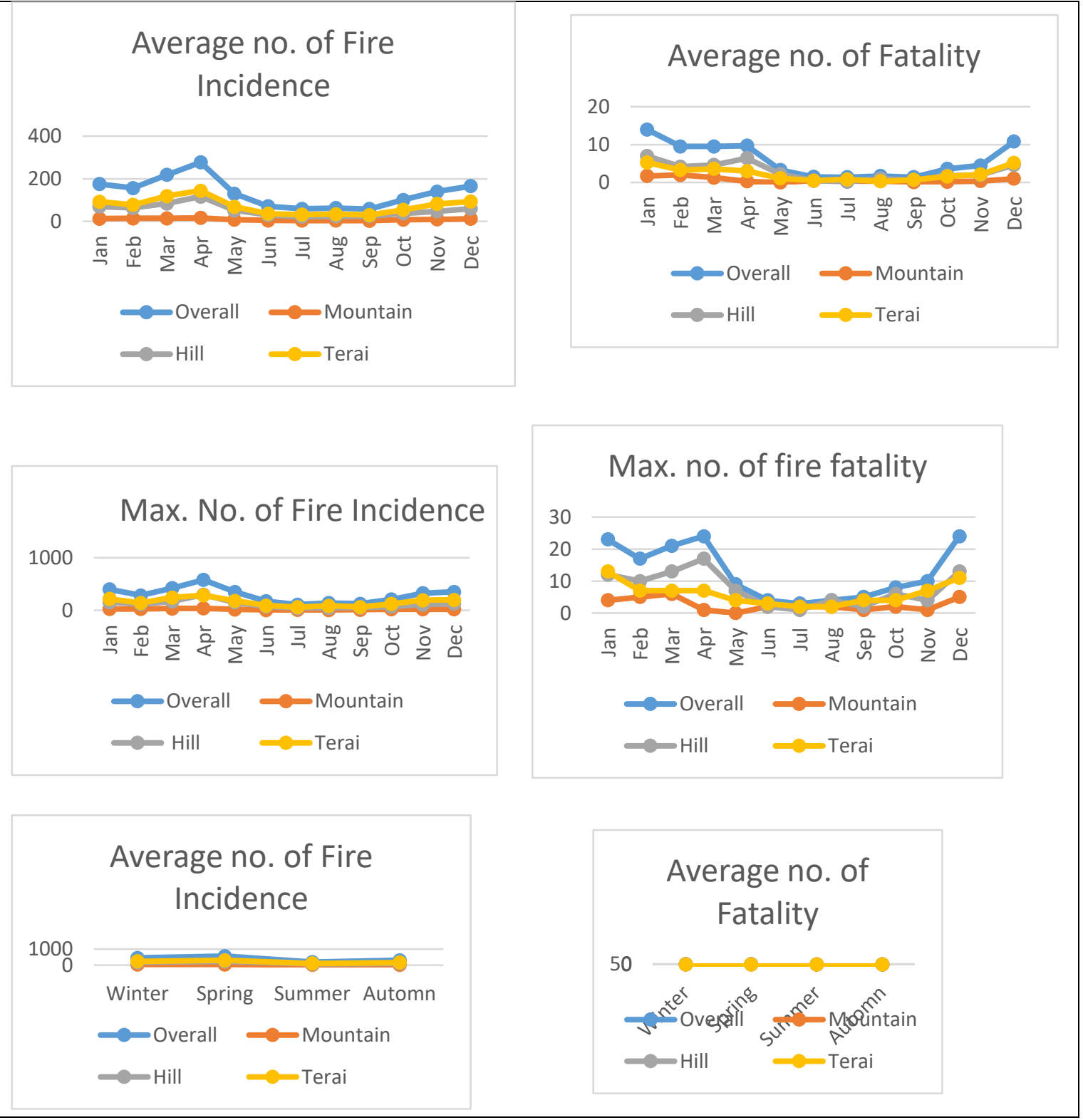

Fig. 3. Line chart showing average number and maximum number of fire frequency and fire fatality.

Table I depicts some simple descriptive statistics like maximum value and average value of the fire incidence and fatality from it by three ecological regions and overall of Nepal. 
Table I: Descriptive statistics of fire incidence and fatality by ecological region.

\begin{tabular}{|c|c|c|c|c|c|c|c|}
\hline \multirow[t]{2}{*}{ Region } & \multirow{2}{*}{$\begin{array}{l}\text { Altitude' in } \\
\text { meters above } \\
\text { sea level }\end{array}$} & \multicolumn{3}{|c|}{$\begin{array}{l}\text { No. of fire incidence in a } \\
\text { month }\end{array}$} & \multicolumn{2}{|c|}{$\begin{array}{l}\text { No. of fatality from } \\
\text { fire incidence in a } \\
\text { month }\end{array}$} & \multirow[t]{2}{*}{$\begin{array}{l}\text { No. of fatality } \\
\text { per } 100 \text { fire } \\
\text { incidences }\end{array}$} \\
\hline & & $\begin{array}{c}\mathrm{Ma} \\
\mathrm{x}\end{array}$ & Mean* & Variance* & Max. & Mean* & \\
\hline Terai & $60-200$ & 289 & 72 & 3379 & 13 & 2 & 3 \\
\hline Hill & $200-4000$ & 299 & 53 & 2088 & 17 & 3 & 6 \\
\hline $\begin{array}{l}\text { Mountai } \\
\mathrm{n}\end{array}$ & $4000-8848$ & 39 & 10 & 60 & 6 & I & 7 \\
\hline Overall & $60-8848$ & 582 & 135 & 11659 & 24 & 6 & 4 \\
\hline
\end{tabular}

* Values are rounded off to its nearest decimal.

The average number of fire incidence was found to be 135 per month in overall of Nepal. It comprised 72 in the Terai followed by 53 in the Hill and 10 in the Mountain. It clearly reflects that number of fire incidence decreased with altitude. Despite the Terai experiencing the highest number of average monthly fire occurrences, it has less fatality per 100 fire incidence (3) followed by the Hill (6) and the Mountain (7). In overall, fatality per 100 fire incidence is found to be 4 .

\section{Model fittings}

The sample data was run in the "Mathwave EasyFit" software of 30 days trial version, it was found that Discrete Uniform, Geometric, Logarithmic, Negative Binomial and Poisson probability distribution as the probable candidate models that might best fit the sample data. However, the CDFs, Survival function and PP plot of the "Mathwave EasyFit" software reflected that empirical curve and theoretical curve for the Discrete Uniform and Logarithmic probability distribution did not match at all which means these two distributions did not fit the data. So only Geometric, Negative Binomial and Poisson distribution were considered as candidate models for the data. Fig. 4, 5, 6 and 7 provides a visual method for evaluating the goodness of fit of the three probability distributions. In the histogram and theoretical densities plots as well as in empirical and theoretical CDF's plots, the theoretical value of negative binomial distribution is seemed to be very close to empirical value which implies that negative binomial distribution is better candidate model among the family of candidate models of the overall data set. The result is same for the Mountain region (Fig. 5), Hill region (Fig. 6) and Terai region (Fig. 7).

The Q - Q plot (Fig. 4, 5, 6 and 7) provides visualized tool for inspecting the best fit of the candidate models, by comparing the quantiles of the empirical distributions to the same quantiles of the theoretical distribution. Points of negative binomial distribution is closer to base line which also reflects that negative binomial distribution is the best for overall fire data. The indication of P-

\footnotetext{
${ }^{1}$ Source:

https://www.dhm.gov.np/uploads/climatic/47171194Climate\%20and\%20Climatic\%20variability \%20of\%20Nepal-2015.pdf
} 

$P$ plot is also in the favor of negative binomial distribution for the overall fire data. The result is same for the Mountain region (Fig. 5), Hill region (Fig. 6) and Terai region (Fig. 7).
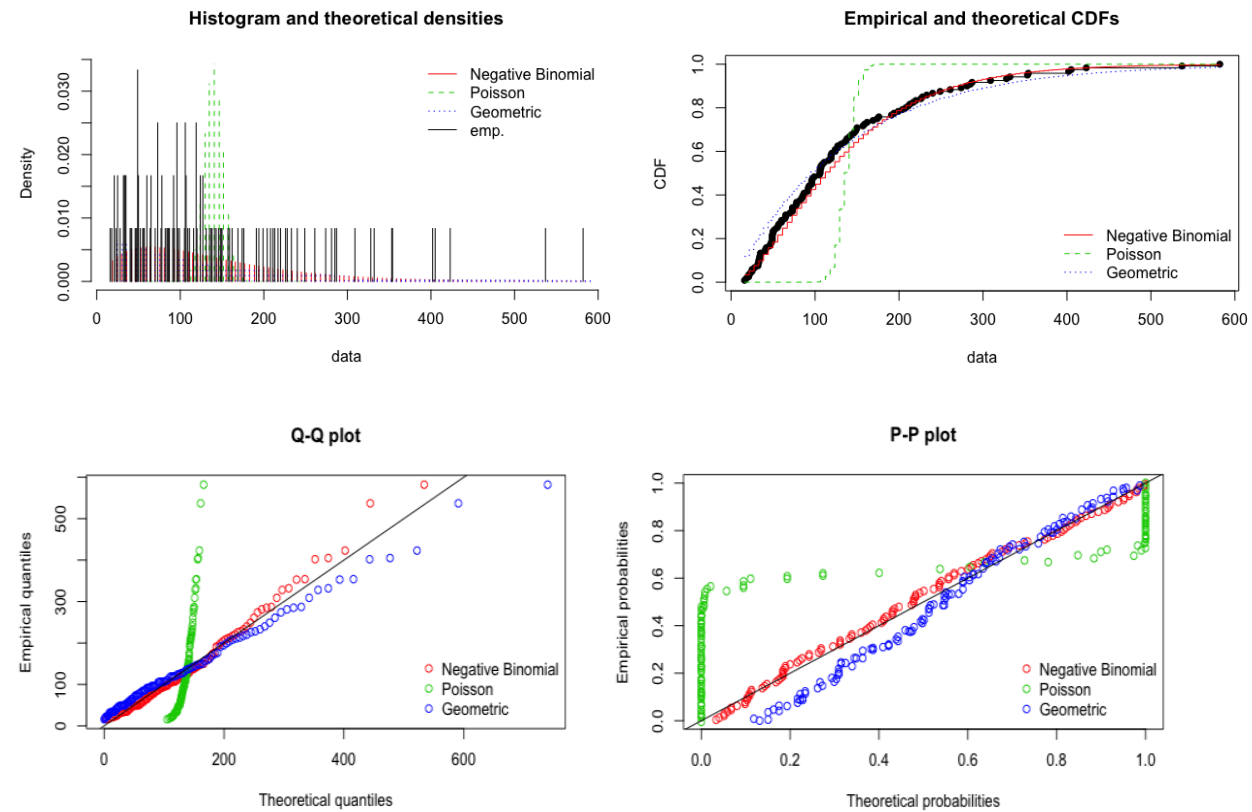

Fig. 4. Histogram and theoretical densities, Empirical and theoretical CDFs, Q-Q plot and P-P plot of the distributions of overall fire data of Nepal.
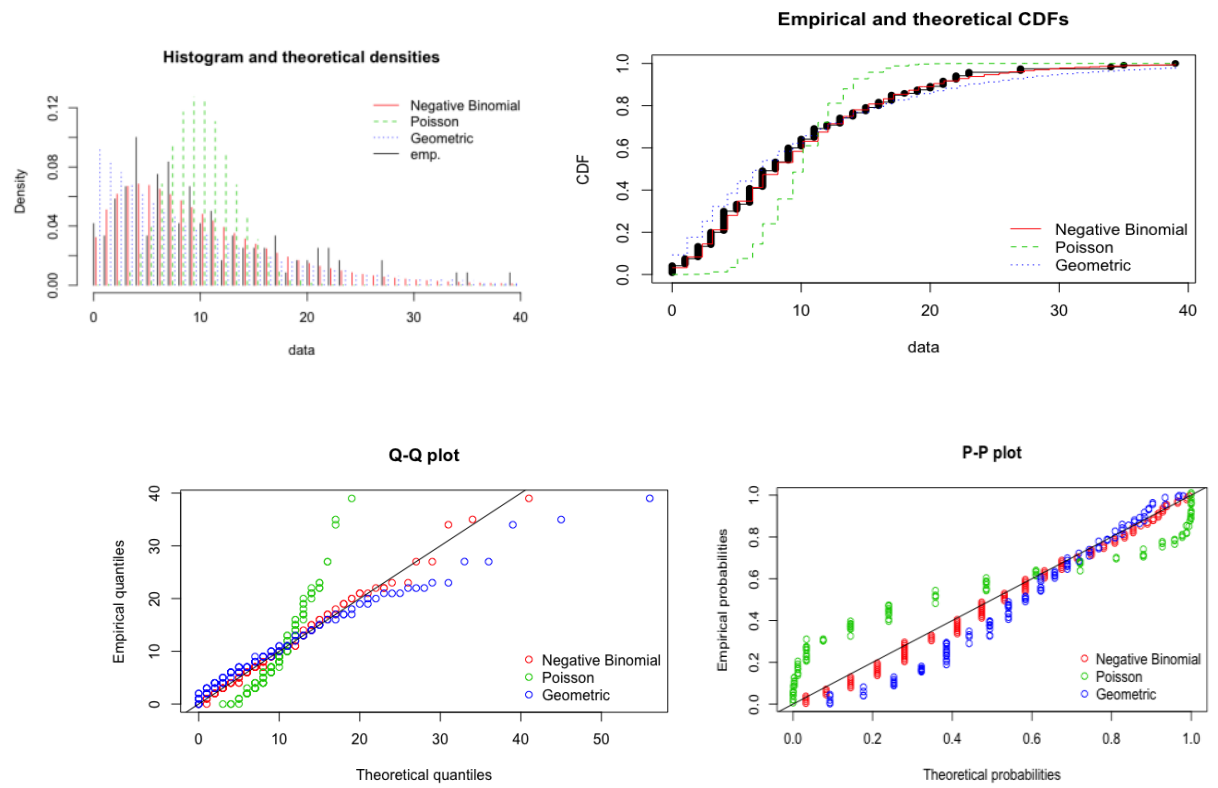

Fig. 5. Histogram and theoretical densities, Empirical and theoretical CDFs, Q-Q plot and P-P plot of the distributions of fire data of Mountain 


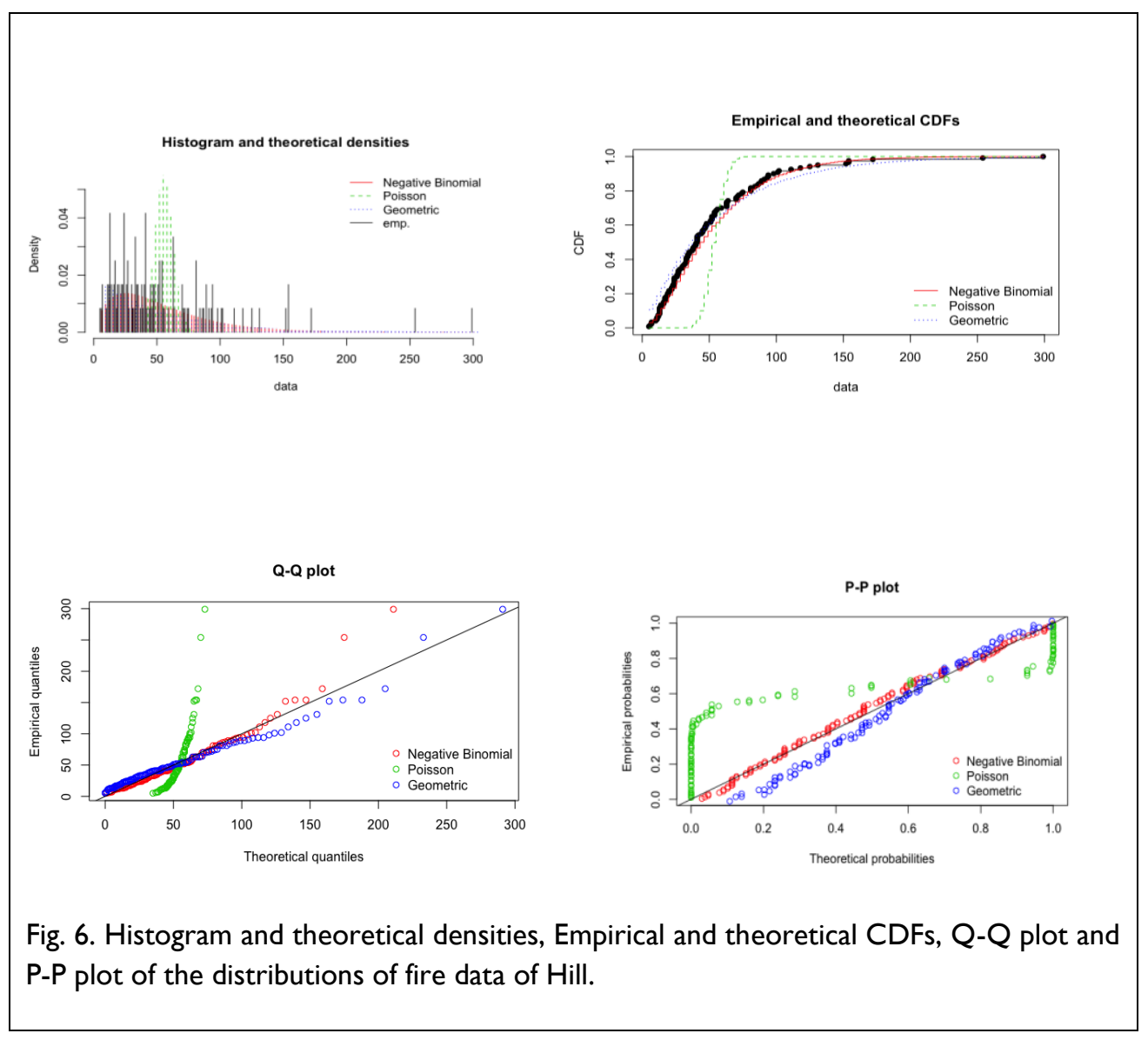

Table 2 shows the parameters estimates of candidate models of the data set by using maximum likelihood estimation. As negative binomial distribution seemed to be better among the candidate models, Terai region received highest mean of monthly fire occurrences (72.09) followed by Hill region (52.7I) and Mountain region (9.78). This depicts that the Terai region is more vulnerable to the monthly fire occurrence. Hence, the occurrence of fire is more frequent in Terai region compared to the Hill and the Mountain. Overdispersion test was also performed by using "AER" package in $\mathrm{R}$ which shows that overall data of fire incidence is over-dispersed (dispersion $=7.45$, $\mathrm{p}$-value $<0.00 \mathrm{I}$ ). This also indicates that negative binomial distribution is good among the candidate models. 
Nep. J. Stat., Vol. 5, 2021

NB distribution for domestic fire incidence in Nepal

Table 2. Parameter estimates with confidence interval for fire frequency.

\begin{tabular}{lcccc}
\hline \multicolumn{1}{c}{$\begin{array}{c}\text { Ecological } \\
\text { Region }\end{array}$} & \multicolumn{2}{c}{ Negative Binomial } & $\begin{array}{c}\text { Poisson } \\
\text { Distribution }\end{array}$ & $\begin{array}{c}\text { Geometric } \\
\text { Distribution }\end{array}$ \\
\cline { 2 - 5 } & $\mathrm{k}$ & $\mu$ & $\mu$ & $\mathrm{P}$ \\
\hline Terai & $1.78 \pm 0.22$ & $72.09 \pm 4.99$ & $72.09 \pm 0.78$ & $0.013 \pm 0.001$ \\
Hill & $1.87 \pm 0.23$ & $52.71 \pm 3.58$ & $52.71 \pm 0.66$ & $0.019 \pm 0.002$ \\
Mountain & $1.88 \pm 0.29$ & $9.78 \pm 0.71$ & $9.78 \pm 0.29$ & $0.093 \pm 0.008$ \\
\hline Overall & $1.87 \pm 0.23$ & $134.60 \pm 9.05$ & $134.58 \pm 1.06$ & $0.007 \pm 0.001$ \\
\hline
\end{tabular}
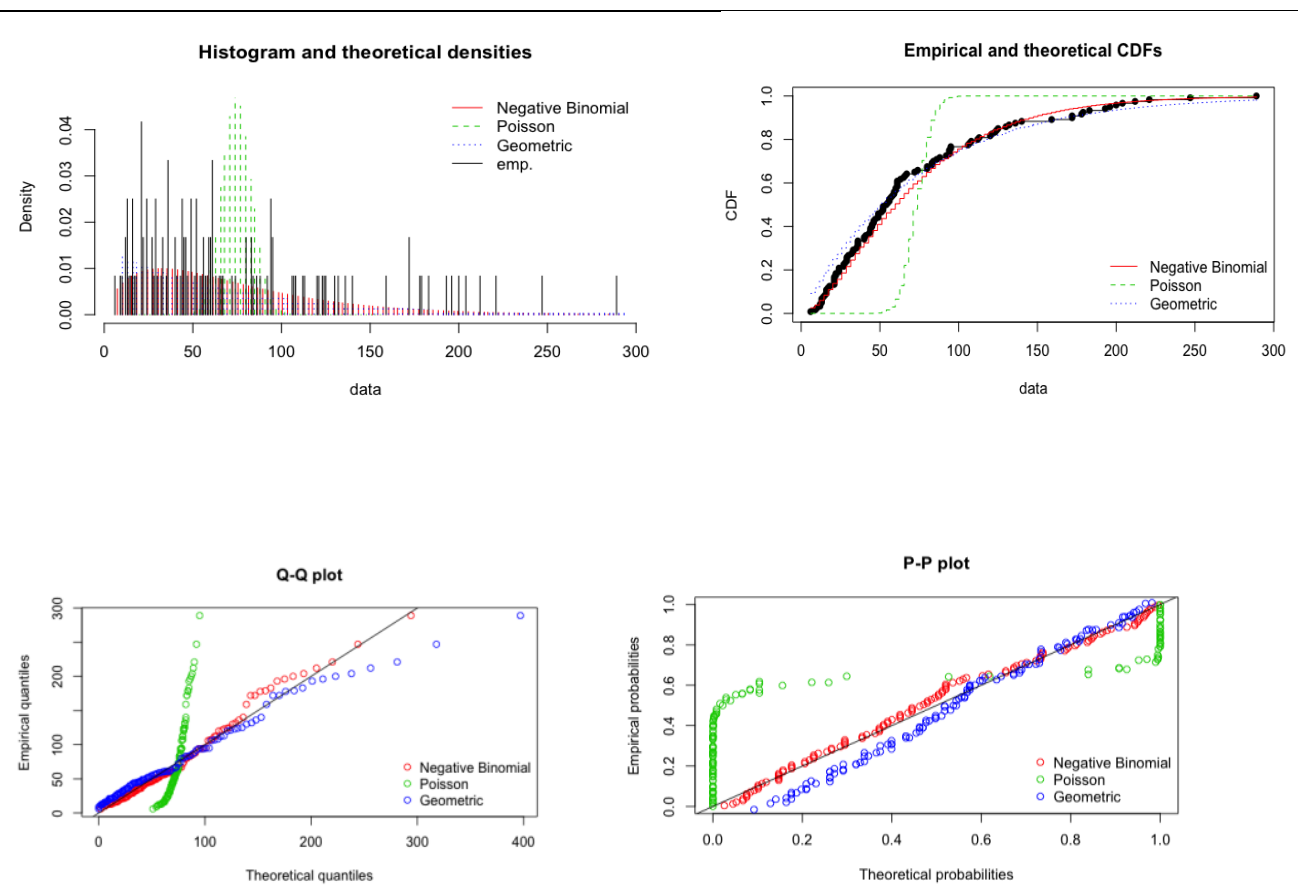

Fig. 7. Histogram and theoretical densities, Empirical and theoretical CDFs, Q-Q plot and P-P plot of the distributions of fire data of Terai.

Table 3. Log likelihood, AIC and BIC statistics of the parameters.

\begin{tabular}{|c|c|c|c|c|c|c|c|c|c|}
\hline \multirow{2}{*}{$\begin{array}{l}\text { Ecological } \\
\text { Region }\end{array}$} & \multicolumn{3}{|c|}{$\begin{array}{l}\text { Negative Binomial } \\
\text { distribution }\end{array}$} & \multicolumn{3}{|c|}{ Poisson distribution } & \multicolumn{3}{|c|}{ Geometric distribution } \\
\hline & $\begin{array}{c}\text { Log } \\
\text { likelihood }\end{array}$ & $\mathrm{AIC}$ & $\mathrm{BIC}$ & $\begin{array}{c}\text { Log } \\
\text { likelihood }\end{array}$ & $\mathrm{AIC}$ & $\mathrm{BIC}$ & $\begin{array}{c}\text { Log } \\
\text { likelihood }\end{array}$ & $\mathrm{AIC}$ & $\mathrm{BIC}$ \\
\hline Terai & -625 & 1253 & 1259 & -2812 & 5627 & 5629 & -634 & 1270 & 1273 \\
\hline Hill & -586 & 1176 & 1182 & $-217 \mid$ & 4345 & 4347 & -597 & 1196 & 1199 \\
\hline Mountain & -392 & 787 & 793 & -570 & $1 \mid 42$ & $1 \mid 45$ & -400 & 801 & 804 \\
\hline Overall & -697 & 1399 & 1404 & -4804 & 9610 & 9612 & -709 & 1419 & 1422 \\
\hline
\end{tabular}


For the further diagnosis of the identified three candidate models, the log-likelihood statistics, the Bayesian Information Criteria (BIC) and Akaike Information Criteria (AIC) are presented in Table 3. The value of log likelihood of the model's parameter is high while AIC and $\mathrm{BIC}$ of the negative binomial distribution in all three ecological regions are less compared to the other two candidate models- Poisson and Geometric, so negative binomial distribution stands ahead among the candidate models.

Table 4. Chi-square statistic and P-value.

\begin{tabular}{lcccccc}
\hline \multirow{2}{*}{$\begin{array}{l}\text { Ecological } \\
\text { Region }\end{array}$} & \multicolumn{2}{c}{$\begin{array}{c}\text { Negative Binomial } \\
\text { distribution }\end{array}$} & \multicolumn{2}{c}{ Poisson distribution } & \multicolumn{2}{c}{ Geometric distribution } \\
\cline { 2 - 7 } & Chi-square & P-Value & Chi-square & P-Value & Chi-square & P-Value \\
\hline Terai & 14.96 & 0.092 & Infinity & 0.000 & 26.20 & 0.003 \\
Hill & 4.74 & 0.785 & $2.49 \times 10^{10}$ & 0.000 & 20.71 & 0.014 \\
Mountain & 3.70 & 0.717 & 1382.22 & 0.000 & 14.17 & 0.048 \\
\hline Overall & 7.48 & 0.588 & Infinity & 0.000 & 22.74 & 0.012 \\
\hline
\end{tabular}

Since AIC and BIC are relative measure of goodness of fit of the distribution, chi square statistics was calculated as the absolute measure of goodness of fit of the model. P value clearly reveals that Negative Binomial distribution statistically fits the fire incidence data of all ecological regions as well as for overall of Nepal at $5 \%$ level of significance whereas Poisson distribution and Geometric distribution does not fit at all (Table 4).

\section{DISCUSSION}

This study finds the probability distribution that best fits the monthly fire occurrence of Nepal. It also seeks the probability model for the same data by three ecological regions: Mountain, Hill and Terai. On the basis of matching between empirical curve and theoretical curve, "Mathewave EasyFit" software suggested Geometric, Negative Binomial and Poisson distribution as candidate models for the data. Findings show that negative binomial distribution is the best model among candidate probability models for the monthly fire occurrences of three ecological regions as well as fire data of entire country. This result is also supported by Boadi, Harvey and Gyeke-dako (2015) who found negative binomial distribution as the best model for the monthly fire occurrence in Ghana. In the empirical monthly fire occurrence data, mean is smaller than its variance indicates that the data is over dispersed. Puig and Valero (2015) and Hilbe (2014) found negative binomial distribution as the best probability model for the over dispersed data.

Comparative study on the data of ecological regions clearly reveals that the Terai region is under the high risk of fire disasters compared to the Hill that is riskier than the Mountain. The fire disaster was found to be low in summer and autumn, and high in spring and winter which reveals that fire incidence might be related with the precipitation and temperature and will be the scope of further research. Fatality per 100 fire occurrence was found to be higher in the Mountain followed by the Hill and then by the Terai. The reason behind this might be geographical 
complication in the Mountain and the Hill. Also, the fatality was observed to be the highest in winter season which may be due to wood/straw burning to get relief from cold in winter.

\section{CONCLUSION}

Nepal is facing different types of disasters. Among them, fires are more recurrent which causes the severe loss of property and human lives. Descriptive statistics shows that occurrences of fire disaster vary with the month. It is moderate during November to February and high in March and April. It is recommended that policy makers should work on an effective fire management to reduce fire occurrence and fire fatality during these months. After exploring the various probability models, Negative binomial distribution fits the best for the monthly fire occurrence data in all ecological regions as well as overall fire incidence in Nepal.

\section{CONFLICT OF INTEREST}

The authors declared that there is no conflict of interest.

\section{ACKNOWLEDGEMENTS}

Authors would like to express sincere gratitude to Prof. Dr. Srijan Lal Shrestha, Prof. Dr. Shankar Pd. Khanal and Associate Prof. Dr. Mrs. Gauri Shrestha for insightful comments and encouragement to complete this paper.

\section{REFERENCES}

Bartak, V., Gdulova, K., Spatenkova, O., Barta, A., \& Simova, P. (20I4). Modelling the probability of building fires. Geoinformatics FCE CTU, 13, 37- 48. doi: http://dx.doi.org/I0.3 I838/jcr.07.07.40 I0.143 I I/gi. I3.5.

Bistinas, I., Harrison, S. P., Prentice, I. C., \& Pereira, J. M. C., (20I4). Causal relationships versus emergent patterns in the global controls of fire frequency. Biogeosciences, I I, 5087-5 I0I. doi: http://dx.doi.org/1010.5 I94/bg-I I-5087-2014.

Boadi, C., Harvey, S. K., \& Gyeke-dako, A. (20I5). Modelling of fire count data: fire disaster risk in Ghana. SpringerPlus 4,794, I-I7. doi: https://doi.org/I0.I I86/s40064-0I5-I585-3.

Bolker B. M. (2008). Ecological models and data in R. Princeton University Press. Retrieved from http://dx.doi.org// 0.2307/j.ctvem4g37.

Burnham, K. P., \& Anderson, D. R. (2004). Multimodel Inference: Understanding AIC and BIC in Model Selection. Sociological Methods \& Research, 33(2), 26I-304.

Retrieved from https://doi.org//0.II77/0049/24I04268644

Cheng, T., \& Wang, J. (2008). Integrated spatio-temporal data mining for forest fire prediction. Transactions in GIS, I2(5), 59I-6II.

Retrieved from http://dx.doi.org/I010.1 I I I/j.I467-967I.2008.0III7.

Cousineau, D., Brown, S., \& Heathcote, A. (2004). Fitting distributions using maximum likelihood: Methods and packages. Behavior Research Methods, Instruments, \& Computers 36, 742756. doi: https://doi.org//0.3758/BF03206555.

D’Este, M., Ganga, A., Elia, M., Lovreglio, R., Giannico, V., Spano, G., Colangelo, G., Lafortezza, R., \& Sanesi, G. (2020). Modeling fire ignition probability and frequency using Hurdle models: a cross-regional study in Southern Europe. Ecol Process 9(54), I-I4. 
doi: https://doi.org/10.|186/s|37|7-020-00263-4.

Dziak, J. J., Coffman, D. L., Lanza, S.L., \& Li, R. (20I2). Sensitivity and specificity of information criteria-technical report. The Methodology Center - The Pennsylvania State University, United States. Retrieved from: https://www.methodology.psu.edu/files/2019/03/I2-II92e90hc6.pdf.

GoN. (202I). Nepal disaster risk reduction portal. Government of Nepal, Kathmandu. Retrieved from http://drrportal.gov.np.

Hilbe, J. M. (20I4). Modeling count data. Cambridge University Press. doi: https://doi.org/10.1017/CBO978II39236065.

Lumley, T., \& Scott, A. (20I5). AIC and BIC for modeling with complex survey data. Journal of Survey Statistics and Methodology, 3(I), I-I8. doi: https://doi.org/I0.1093/jssam/smu02I. Mckenzie, D., Petereson, D. L., \& Agee, J. K. (2000). Fire frequency in the interior Columbia River Basin: building regional models from fire history data. Ecological Applications, 10(5), I497I516. doi: https://doi.org/I0.1890/I05I-076I(2000)0I0[I497:FFITIC]2.0.CO;2.

Ministry of Home Affairs. (2019). Nepal Disaster Report, 20I, Government of Nepal.

Retrieved from http://drrportal.gov.np/uploads/document/I594.pdf.

O'Hara, R. B., \& Kotze, D. J. (2010). Do not log-transform count data. Methods in Ecology and Evolution, I(2), I I8-122. doi: https://doi.org/I0.I I I I/j.204I-2I0X.2010.0002I.x.

Puig, P., \& Valero, J. (2006). Count data distributions: some characterizations with applications. Journal of the American Statistical Association, I0I(473), 332-340. doi: https://doi.org/10.1 198/0162145050000007/8.

Taylor, S., Woolford, D., Dean, C., \& Martell, D. (2013). Wildfire prediction to inform management: statistical science challenges. Statistical Science, 28(4), 586-6I5. Retrieved from http://www.jstor.org/stable/43288437.

UNDRR. (2019). Sendai Framework for disaster risk reduction. Retrieved from https://www.desinventar.net/DesInventar/profiletab.jsp?countrycode=g I 7\&continue=y.

Walsh, G. R. (1975), "Gradient methods for unconstrained optimization," in methods of optimization. John Wiley and Sons, London, 105-142. Cited by: Swanson, W. L. (1997). Negative binomial estimation and testing: comparison to minimum disparity methods. Montana State University-Bozeman, Bozeman, Montana-Ph. D thesis dissertation.

Wang, F., Lu, S. and Li, C., (2005). Analysis of fire statistics of China: Fire frequency and fatalities in fires. Fire Safety Science, 8, 353-362. doi: https://doi.org/10.380 I/IAFSS.FSS.8-353.

WHO. (2018). Burns. Retrieved from https://www.who.int/news-room/fact-sheets/detail/burns.

Xiao, Y., Zhang, X., \& Ji, P. (20I5). Modeling forest fire occurrences using count-data mixed models in Qiannan Autonomous Prefecture of Guizhou Province in China. PLoS One, 10(3). doi: https://doi.org/I0.137I/journal.pone.012062I.

Zhang, J., Yao, F., Liu, C., Yang, L., \& Boken, V. K. (20I I). Detection, emission estimation and risk prediction of forest fires in China using satellite sensors and simulation models in the past three decades-an overview. International Journal of Environmental Research and Public Health, 8, 3156-3I78. doi: https://doi.org/I0.3390/ijerph8083I56. 
Reference to this paper should be made as follows:

Yadav, A. K., \& Shah, S. K. (2021). Negative binomial distribution to explain the domestic fire incidence in Nepal. Nep. J. Stat, 5, 5I-66. 